\title{
Antioxidative Changes of Blueberry Leaf Extracts in Emulsion-Type Sausage during In Vitro Digestion
}

\author{
Sun-Jin Hur, Doo-Hwan Kim, Se-Chul Chun and Si-Kyung Lee* \\ Department of Bioresources and Food Science, Konkuk University, Seoul 143-701, Korea
}

\begin{abstract}
This study was conducted to investigate the effects of in vitro human digestion on the antioxidant activity of blueberry leaf extracts (BLE) in emulsion-type sausages (ETS). Leaves from four cultivars of blueberries (Bluecrop, Bluegold, Duke, and Northland) collected from a wild blueberry farm were extracted with $80 \%$ ethanol. ETS were prepared with $0.2 \%$ BLE. The samples were then passed through an in vitro human digestion system which simulates the composition of the mouth, stomach, and small intestine juice. Only one phenolic compound (chlorogenic acid) was detected in the BLE. Northland BLE had appreciably higher amounts of chlorogenic acid than that of other BLE, both before and after in vitro human digestion. Antioxidant activity of any BLE was not influenced by in vitro human digestion, whereas the antioxidant activity of chlorogenic acid standard increased in response to in vitro human digestion in both 2,2-azino-bis(3-ethylbenzothiazoline-6-sulfonic acid (ABTS) and ferric-reducing ability of plasma (FRAP). In the present study, the antioxidant activities of the BLE were not strongly influenced by in vitro human digestion, and the antioxidant activity depended on the chlorogenic acid content of ETS. Thus, compounds from blueberry leaves may have important applications in the future as natural antioxidants for meat products.
\end{abstract}

Key words: antioxidant activity, blueberry leaf, emulsion-type sausage, in vitro human digestion

\section{Introduction}

Emulsion-type sausage (ETS) is usually made from ground meat with high fat content $(20-50 \%)$, which renders it prone to lipid oxidation during storage. Thus, numerous studies have been conducted to develop natural antioxidants such as flavonoids, phenolic compounds, or vitamins for meat products. In general, fruits and vegetables contain many different phyto-nutrients, many of which have antioxidant properties (Ehlenfeldt and Prior, 2001). In particular, among the berry fruits, blueberries (Vaccinium corymbosum L.) are considered to be a good source of phenolic compounds and are well known for their high antioxidant activity scores (Prior et al., 1998). Chlorogenic acids are family of esters formed between certain trans-cinnamic acids and quinic acid which is the major phenolic compounds found in numerous plant species. Chlorogenic acids have the phenolic groups enabling them to act as the natural antioxidant.

\footnotetext{
*Corresponding author: Si-Kyung Lee, Department of Bioresources and Food Science, Konkuk Univeristy, Seoul 143-701, Korea. Tel: 82-2-450-3759, Fax: 82-2-450-3726, E-mail: lesikyung@konkuk.ac.kr
}

Significant differences in the phenolic content and antioxidant activities occur between individual blueberry species, as well as between varieties (Prior et al., 1998), and the changes in phenolic composition and content are influenced by postharvest storage, handling, and processing (Prior et al., 1998). Therefore, individual species of blueberry may harbor different phytochemical contents and display different antioxidant effects.

Furthermore, the absorption of certain micronutrients by the human body may be influenced by the concomitant ingestion of other substances. The bioavailability of polyphenols to peripheral tissues can be diminished by high intestinal and biliary secretion of their conjugates (Bermúdez-Soto et al., 2007; Silberberg et al., 2006). Previous studies (Bermúdez-Soto et al., 2007) have shown that dietary polyphenols are highly sensitive to the mild alkaline conditions in the small intestine and these previous findings suggest that, during duodenal digestion, a proportion of these compounds may be transformed into different structural forms with different chemical properties. Although several studies have been conducted to develop new ingredients as antioxidants for meat processing, the changes in antioxidant activities upon ingestion have not been extensively determined in ETS. Thus, the 
present study aims to determine the effect of in vitro human digestion on the antioxidant activity of blueberry leaf extracts in ETS.

\section{Materials and Methods}

\section{Sausage formulation and processing}

Lean pork and back fat were purchased from a local meat processing plant. Excess fat was trimmed from the meat and the lean muscle was diced into approximately 2 cubes $(8 \times 4 \times 2 \mathrm{~cm})$ and ground through a $7-\mathrm{mm}$ diameter orifice using a mincer. Ground meat was cured with phosphate and $\mathrm{NaCl}$ using a meat mixer for $24 \mathrm{~h}$ at $4^{\circ} \mathrm{C}$. Cured meat was placed in a bowel cutter along with sausage seasoning (salt $73.5 \%$, dextrose $11.4 \%$, sage powder $7.3 \%$, monosodium glutamate $1.4 \%$, red pepper $3 \%$, nutmeg $3 \%$ and nitrite $0.4 \%$ ) water and different kind of $0.2 \%$ BLE stipulated in the experiment design. Chopping was continued until the batter temperature reached to $10^{\circ} \mathrm{C}$. The emulsified meat batters were stuffed into PVDC casings ( $30 \mathrm{~mm}$ diameter) and placed in a cooking chamber pre-programmed to operate at $65^{\circ} \mathrm{C}$ for $30 \mathrm{~min}$. Next, the temperature was increased to $75^{\circ} \mathrm{C}$ and maintained for 30 $\min$. Finally, the temperature was increased further to $80^{\circ} \mathrm{C}$ and this was maintained for $20 \mathrm{~min}$. After cooling in ice water for $20 \mathrm{~min}$, the ETS were stored at $5^{\circ} \mathrm{C}$ until further use.

\section{In vitro human digestion}

The in vitro human digestion model used was a modi- fied version of a previously described one (Hur et al., 2009; Versantvoort et al., 2005). The model contained the following components:

I. Pre-ingestion: The ETS containing BLE.

II. Mouth: About $3 \mathrm{~g}$ of sample was mixed with $6 \mathrm{~mL}$ of simulated saliva fluid (pH 6.8) and then stirred for 5 $\min$ at $37^{\circ} \mathrm{C}$.

III. Stomach: Approximately $12 \mathrm{~mL}$ of simulated gastric fluid ( $\mathrm{pH}$ 2) was added, and then the mixture was stirred for $2 \mathrm{~h}$ at $37^{\circ} \mathrm{C}$.

IV. Small Intestine: Approximately $12 \mathrm{~mL}$ of duodenal juice, $6 \mathrm{~mL}$ of bile juice, and $2 \mathrm{~mL}$ of $\mathrm{HCO}_{3}$ solution $(\mathrm{pH}$ 6.5-7) were added, and the mixture was stirred for $2 \mathrm{~h}$ at $37^{\circ} \mathrm{C}$.

The compositions of the simulated saliva, gastric, duodenal, and bile fluids are presented in Table 1. During the digestion, the samples were swirled $(60 \mathrm{rpm})$ on a shaking water bath (Model HB-205SW, Hanbaek Scientific Co., Korea) to simulate the motility of the gastrointestinal tract.

\section{Plant materials}

Leaves from four blueberry cultivars were collected from a wild blueberry farm. Bluecrop blueberry has a firm light blue medium-sized fruit and bluecrop is generally considered the best all around variety for adaptability, long production period, good fruit yield and disease resistance (Anonym, 2013). Bluegold is a mid-season variety that is highly productive, with superior quality berries for midseason (Anonym, 2013). Bluegold has medium-

Table 1. Constituents and concentrations of the various synthetic juices of the in vitro human digestion model representing fed conditions

\begin{tabular}{|c|c|c|c|c|}
\hline & Saliva & Gastric juice & Duodenal juice & Bile juice \\
\hline \multirow{6}{*}{$\begin{array}{l}\text { Inorganic } \\
\text { components }\end{array}$} & $10 \mathrm{ml} \mathrm{KCl} 89.6 \mathrm{~g} / \mathrm{L}$ & $15.7 \mathrm{ml} \mathrm{NaCl} 175.3 \mathrm{~g} / \mathrm{L}$ & $40 \mathrm{ml} \mathrm{NaCl} 175.3 \mathrm{~g} / \mathrm{L}$ & $30 \mathrm{ml} \mathrm{NaCl} 175.3 \mathrm{~g} / \mathrm{L}$ \\
\hline & $10 \mathrm{ml} \mathrm{KSCN} 20 \mathrm{~g} / \mathrm{L}$ & $3.0 \mathrm{ml} \mathrm{NaH}{ }_{2} \mathrm{PO}_{4} 88.8 \mathrm{~g} / \mathrm{L}$ & $40 \mathrm{ml} \mathrm{NaHCO} 384.7 \mathrm{~g} / \mathrm{L}$ & $68.3 \mathrm{ml} \mathrm{NaHCO} 384.7 \mathrm{~g} / \mathrm{L}$ \\
\hline & $10 \mathrm{ml} \mathrm{NaH}{ }_{2} \mathrm{PO}_{4} 88.8 \mathrm{~g} / \mathrm{L}$ & $9.2 \mathrm{ml} \mathrm{KCl} 89.6 \mathrm{~g} / \mathrm{L}$ & $10 \mathrm{ml} \mathrm{KH}{ }_{2} \mathrm{PO}_{4} 8 \mathrm{~g} / \mathrm{L}$ & $4.2 \mathrm{ml} \mathrm{KCl} 89.6 \mathrm{~g} / \mathrm{L}$ \\
\hline & $10 \mathrm{ml} \mathrm{NaSO}{ }_{4} 57 \mathrm{~g} / \mathrm{L}$ & $18 \mathrm{ml} \mathrm{CaCl} \cdot 2 \mathrm{H}_{2} \mathrm{O} 22.2 \mathrm{~g} / \mathrm{L}$ & $6.3 \mathrm{ml} \mathrm{KCl} 89.6 \mathrm{~g} / \mathrm{L}$ & $150 \mu \mathrm{lHCl} 37 \% \mathrm{~g} / \mathrm{g}$ \\
\hline & $1.7 \mathrm{ml} \mathrm{NaCl} 175.3 \mathrm{~g} / \mathrm{L}$ & $10 \mathrm{ml} \mathrm{NH}{ }_{4} \mathrm{Cl} 30.6 \mathrm{~g} / \mathrm{L}$ & $10 \mathrm{ml} \mathrm{MgCl}{ }_{2} 5 \mathrm{~g} / \mathrm{L}$ & \\
\hline & $20 \mathrm{ml} \mathrm{NaHCO}{ }_{3} 84.7 \mathrm{~g} / \mathrm{L}$ & $6.5 \mathrm{ml} \mathrm{HCl} \mathrm{37 \% g/g}$ & $180 \mu \mathrm{l} \mathrm{HCl} \mathrm{37 \% g/g}$ & \\
\hline \multirow{5}{*}{$\begin{array}{c}\text { Organic } \\
\text { components }\end{array}$} & $8 \mathrm{ml}$ urea $25 \mathrm{~g} / \mathrm{L}$ & $10 \mathrm{ml}$ glucose $65 \mathrm{~g} / \mathrm{L}$ & $4 \mathrm{ml}$ urea $25 \mathrm{~g} / \mathrm{L}$ & $10 \mathrm{ml}$ urea $25 \mathrm{~g} / \mathrm{L}$ \\
\hline & & $10 \mathrm{ml}$ glucuronic acid $2 \mathrm{~g} / \mathrm{L}$ & & \\
\hline & & $3.4 \mathrm{ml}$ urea $25 \mathrm{~g} / \mathrm{L}$ & & \\
\hline & & $10 \mathrm{ml}$ glucosamine & & \\
\hline & & hydrochloride $33 \mathrm{~g} / \mathrm{L}$ & & \\
\hline \multirow{4}{*}{$\begin{array}{l}\text { Add to mixture of } \\
\text { organic+inorganic } \\
\text { components }\end{array}$} & $290 \mathrm{mg} \alpha$-amylase & $1 \mathrm{~g} \mathrm{BSA}$ & $9 \mathrm{ml} \mathrm{CaCl} 2 \cdot 2 \mathrm{H}_{2} \mathrm{O} 22.2 \mathrm{~g} / \mathrm{L}$ & $10 \mathrm{ml} \mathrm{CaCl} 2 \cdot 2 \mathrm{H}_{2} \mathrm{O} 22.2 \mathrm{~g} / \mathrm{L}$ \\
\hline & $15 \mathrm{mg}$ uric acid & $2.5 \mathrm{~g}$ pepsin & $1 \mathrm{~g} \mathrm{BSA}$ & $1.8 \mathrm{~g} \mathrm{BSA}$ \\
\hline & $25 \mathrm{mg}$ mucin & $3 \mathrm{~g}$ mucin & $9 \mathrm{~g}$ pancreatin & $30 \mathrm{~g}$ bile \\
\hline & & & $1.5 \mathrm{~g}$ lipase & \\
\hline $\mathrm{pH}$ & $6.8 \pm 0.2$ & $1.30 \pm 0.02$ & $8.1 \pm 0.2$ & $8.2 \pm 0.2$ \\
\hline
\end{tabular}

The inorganic and organic components are augmented to $500 \mathrm{~mL}$ with distilled water.

If necessary, the $\mathrm{pH}$ of the juices would be adjusted to the appropriate value. 
sized fruit with small, and dry blossom scars. It has good flavor and firmness (Weber, 2012). Duke blueberry is considered the best early season cultivar available. The fruit size and quality is very good but the flavor can be bland if picked late (Weber, 2012). Northland blueberry is an extremely productive half-high type with medium sized, dark and soft fruit (Weber, 2012). The leaves were separated from other debris by hand, dried for $10 \mathrm{~d}$ at room temperature, and then stored in sealed polyethylene bags at $-20^{\circ} \mathrm{C}$.

\section{Preparation of blueberry leaf extracts}

Each phenolic extract of freeze-dried blueberry leaves (particle size, 60 mesh) was obtained as follows. Powdered blueberry leaves (50 g) were suspended for $2 \mathrm{~h}$ in and extracted with $500 \mathrm{~mL}$ of $80 \%$ ethanol at $70^{\circ} \mathrm{C}$. The extracts were then filtered through Whatman No. 2 filter paper (Whatman International Limited, England), and the filtrate was evaporated to dryness. Subsequently, the filtrate was frozen and lyophilized. The extracts were then placed in a glass bottle and stored at $-20^{\circ} \mathrm{C}$ until use.

\section{Determination of total phenolics}

The total phenolics were determined by spectrophotometry (Jeong et al., 2010). The standard curve for total phenolics was obtained from gallic acid standard solution (0$100 \mathrm{mg} / \mathrm{L}$ ). The total phenolics in extract from the four cultivars of blueberry leaves were expressed as milligrams of gallic acid equivalents (GAE) per gram of sample.

\section{Quantification of chlorogenic acid using HPLC}

The content of chlorogenic acid in the phenolic extracts obtained from the leaves of each of the four cultivars was determined at $280 \mathrm{~nm}$ using a diode array UV-visible detector (Agilent 1100 series, Agilent Co., USA) by using chlorogenic acid standard solution. The components of the extracts were separated on a Shiseido C18 column (250 $\mathrm{mm} \times 4.6 \mathrm{~mm}$ id, $5 \mu \mathrm{m}$, Shiseido Co., Japan). The elution solvents were (A) $0.01 \mathrm{M}$ potassium phosphate buffer adjusted to $\mathrm{pH} 3.0$ by phosphoric acid and (B) methanol. The solvent gradient elution program used was as follows: initial 90\% (A), hold for $9.5 \mathrm{~min}$; linear gradient to $68 \%$ (A) in $3.5 \mathrm{~min}$; linear gradient to $67 \%$ (A) 17 min; linear gradient to $20 \%$ (A) in $1 \mathrm{~min}$; linear gradient to $90 \%$ (A) in $1 \mathrm{~min}$, hold for $10 \mathrm{~min}$. The flow rate was constant at $1.5 \mathrm{~mL} / \mathrm{min}$. Chlorogenic acid was identified by comparing retention times and ultraviolet spectra with those of known standards and was quantified using the relevant peak areas in the chromatograms. All analyses were run in triplicates and mean values were calculated. Content of chlorogenic acid was expressed in $\mathrm{mg} / \mathrm{g}$ extract.

\section{ABTS radical-scavenging activity}

2,2-azino-bis(3-ethylbenzothiazoline-6-sulfonic acid (ABTS) was dissolved in water to attain a concentration of $7 \mathrm{mM} / \mathrm{L}$ ABTS reagent stock was produced by reacting the ABTS stock solution with $2.45 \mathrm{mmol} / \mathrm{L}$ potassium persulfate (final concentration) and allowing the mixture to stand in the dark at room temperature for $12-16 \mathrm{~h}$ before use. The working ABTS reagent solution was prepared by diluting the ABTS reagent stock with phosphate-buffered saline ( $5 \mathrm{mmol} / \mathrm{L}, \mathrm{pH} 7.4)$ adjusted to an absorbance of 0.70 at $734 \mathrm{~nm}$. For testing the samples, $1.0 \mathrm{~mL}$ of ABTS working reagent standard was added to $0.5 \mathrm{~g}$ of the sample and absorbance was determined at 5 min after the initial mixing (Jeong et al., 2010). The ABTS-scavenging activity was expressed as percent ABTS scavenging and was calculated from the following formula:

$\%$ ABTS scavenging activity $=[$ (control absorbance sample absorbance) / (control absorbance) $] \times 100$

\section{Ferric-reducing ability of plasma (FRAP) assay}

The FRAP assay was performed according to the protocol developed in a previous study (Jeong et al., 2010). Briefly, $1.5 \mathrm{~mL}$ of working FRAP reagent (10 vol of 300 $\mathrm{mmol} / \mathrm{l}$ acetate buffer, $\mathrm{pH} 3.6+1 \mathrm{vol}$ of $10 \mathrm{mmol} / \mathrm{L} \mathrm{2,4}$, 6-tripyridyl-S-triazine in $40 \mathrm{mmol} / \mathrm{L} \mathrm{HCl}+1$ vol of 20 $\mathrm{mmol} / \mathrm{L} \mathrm{FeCl}_{3}$ ) that had been pre-warmed to $37^{\circ} \mathrm{C}$ was added to $50 \mu \mathrm{l}$ of test samples and standards. This was mixed by vortexing and maintained at $37^{\circ} \mathrm{C}$. Then, the absorbance at $593 \mathrm{~nm}$ was determined against a reagent blank at a predetermined time within a time window of 0 4 min after mixing of the sample and reagent.

\section{Statistical analysis}

Statistical analyses were done for 3 batches for emulsion-type sausage. Data for each batch of emulsion-type sausage collected for total phenolic content, chlorogenic acid content, ABTS and FRAP were analyzed using ANOVA with SAS software (SAS Inst. Inc., USA). Significant differences $(p<0.05)$ between mean values of quintuplicate samples were determined for total phenolic content, chlorogenic acid content, ABTS and FRAP. 


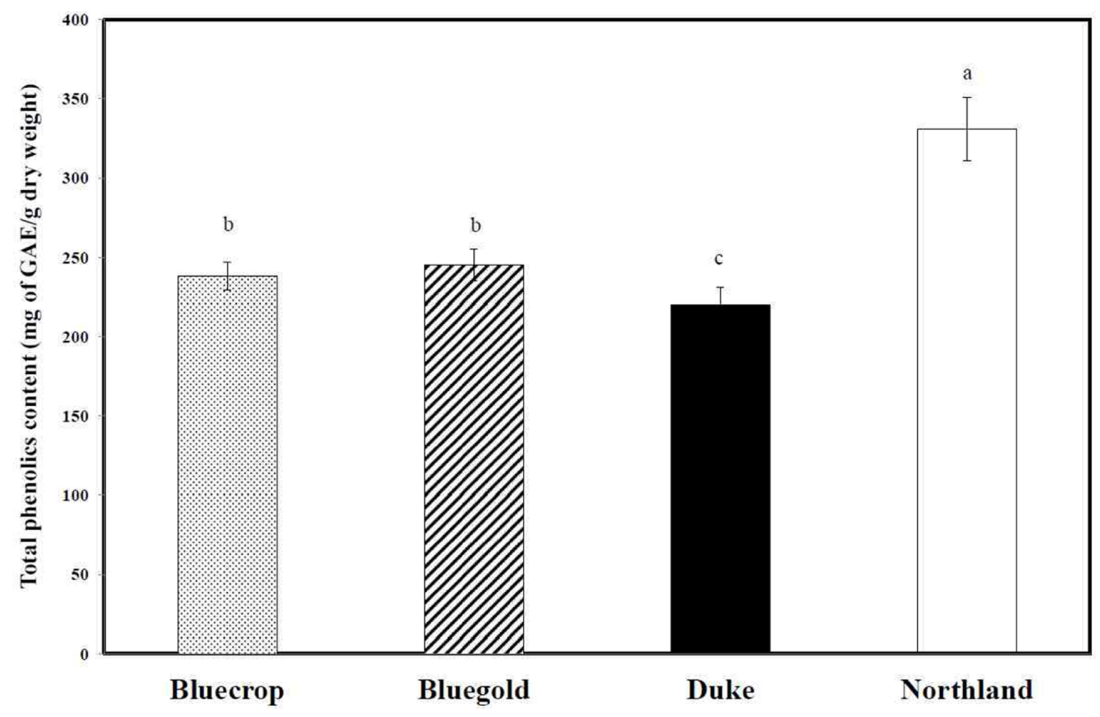

Fig. 1. Total phenolic content of extracts from the leaves of four cultivars of blueberry. Different letters indicate significant difference at $p<0.05$.

\section{Results and Discussion}

The total phenolic contents of BLE from the four cultivars (Fig. 1) were 268.50-331.17 mg GAE/g. The phenolic extract from the Northland cultivar showed the highest total phenolic content $(331.17 \mathrm{mg} \mathrm{GAE} / \mathrm{g})$, whereas that from the Duke cultivar (268.50 mg GAE/g) contained the least total phenolic content.

The chlorogenic acid content of ETS containing BLE during in vitro human digestion is presented in Fig. 2. Specifically, the ETS containing Northland BLE had higher content of chlorogenic acid than the ETS contain- ing BLE from other cultivars before and after in vitro human digestion. The fruit of blueberries is known to be a rich source of phenolic acids, catechins, flavonols, anthocyanins, and condensed tannins (Naczk et al., 2006). Blueberry extract is largely composed of anthocyanins, chlorogenic acid, epicatechin, and glycosides of ferulic acid and quercetin (Stevenson et al., 2007). However, in the present study, only one phenolic compound (chlorogenic acid) was detected in ETS containing BLE. This difference could be due to the difference in the sources of phenolic compounds, namely, the blueberry fruit and blueberry leaf (Sellappan et al., 2002; Kim et al., 2009).

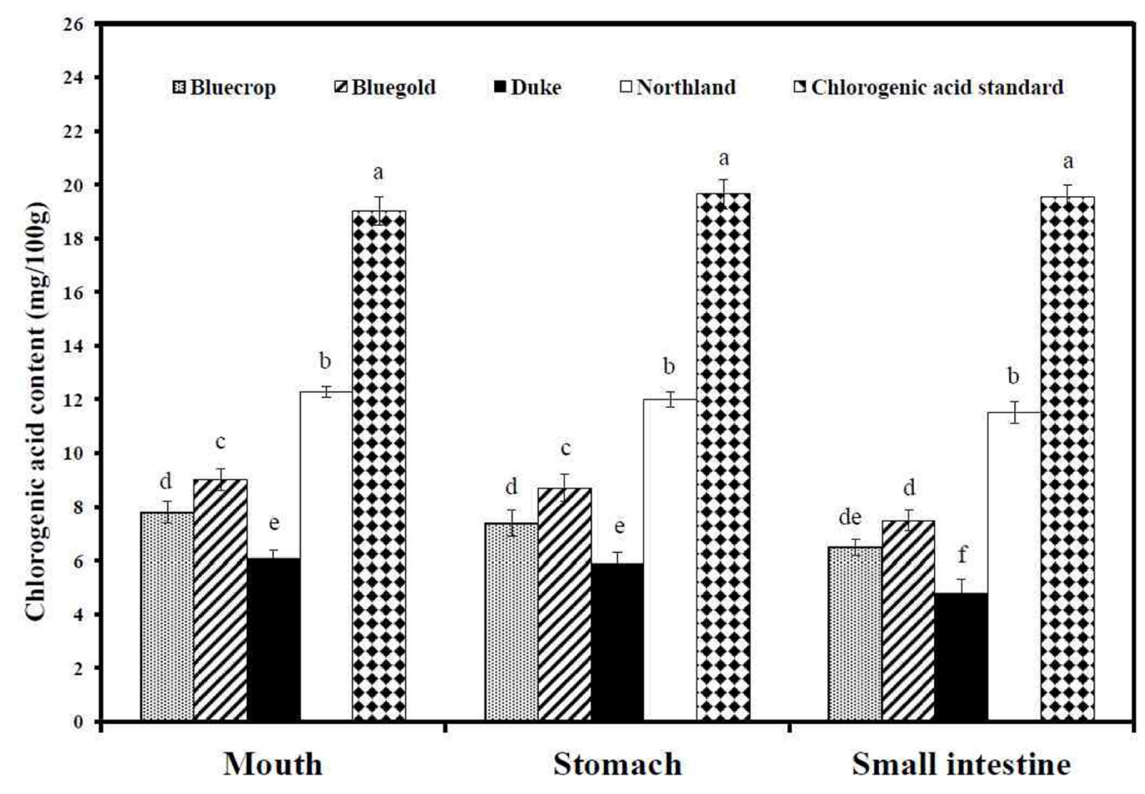

Fig. 2. Chlorogenic acid content of emulsion-type sausage containing four cultivars of blueberry leaf extracts as they pass through an in vitro human digestion model. Different letters indicate significant difference at $p<0.05$. 
The phenolic contents in the BLE from the cultivars tested also differed because of the differences in the seasonal and geographic origins of the various cultivars, which are known to contribute to the characteristics of the phenolic compounds they contain (Sellappan et al., 2002). Following digestion, the amount of chlorogenic acid in all ETS decreased. This decrease was particularly pronounced when the samples moved from the simulated stomach to the small intestine (Fig. 2). Moreover, unknown compounds appeared in all ETS containing BLE after digestion in the small intestine (data not shown). Our results disagreed with those of a previous study (Bermúdez-Soto et al., 2007), indicating that most dietary polyphenols remain quite stable during gastric digestion. Conversely, dietary polyphenols display high sensitivity to the mild alkaline conditions in the small intestine, which may result in their transformation to different structural forms with altered chemical properties during duodenal digestion (Bermúdez-Soto et al., 2007). Another study (McDougall et al., 2005) also reported that the $\mathrm{pH}$ shift to $>7.5$ during pancreatic and/or small intestinal digestion was the main factor responsible for the irreversible breakdown of the anthocyanins. In the present study, the content of chlorogenic acid in ETS containing BLE changed upon entry of the sample into the small intestine. This change may be attributed to the differing $\mathrm{pH}$ values between the stomach and small intestine during in vitro human digestion, as well as to chlorogenic acid-bile acid
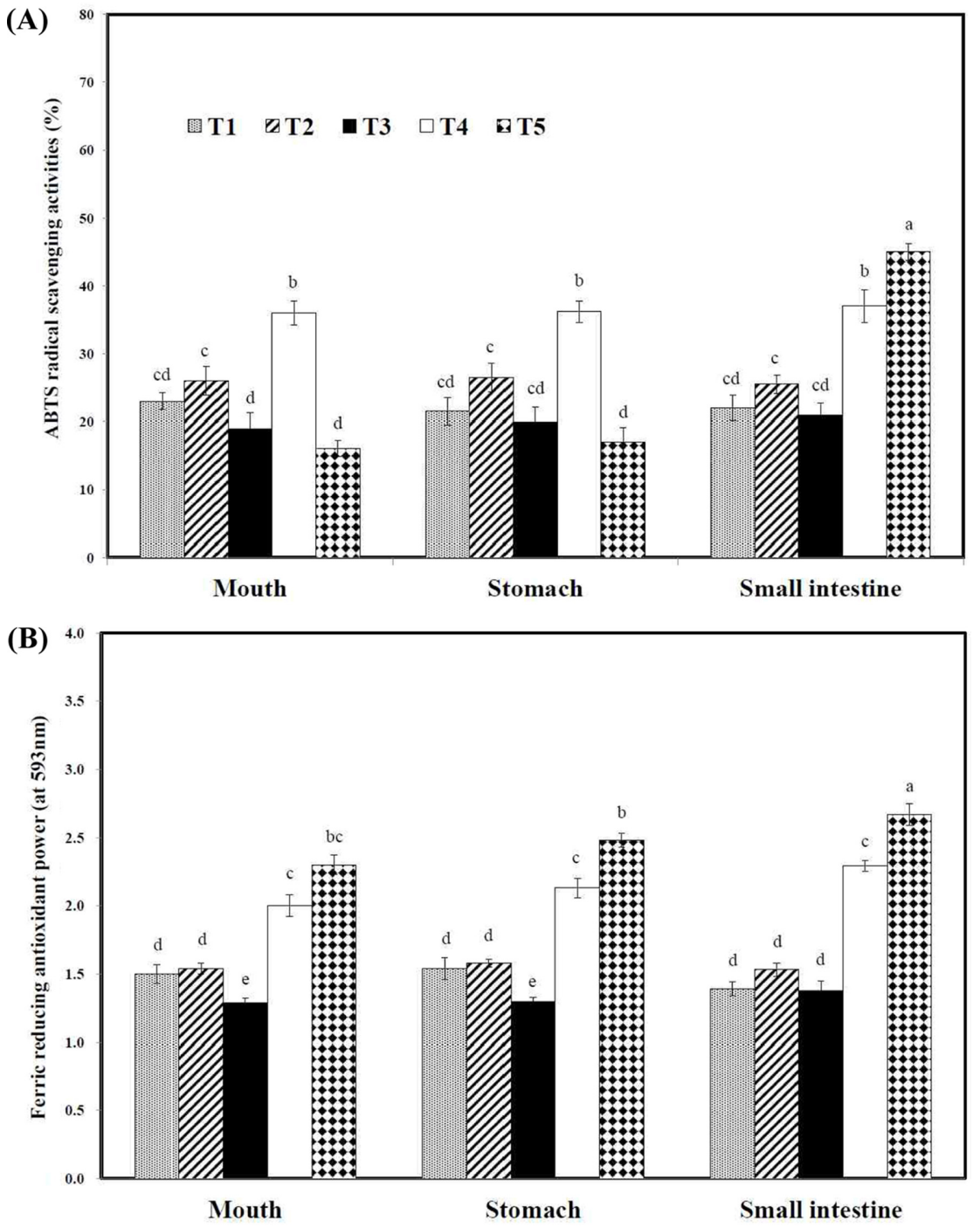

Fig. 3. ABTS (A) FRAP (B) of emulsion-type sausage containing four cultivars of blueberry leaf extracts and chlorogenic acid standard as they pass through an in vitro human digestion model. $\mathrm{T} 1$ : sausage with $0.2 \%$ Bluecrop blueberry leaf extract, $\mathrm{T} 2$ : sausage with $0.2 \%$ Bluegold blueberry leaf extract, T3: sausage with $0.2 \%$ Duke blueberry leaf extract, T4: sausage with $0.2 \%$ Northland blueberry leaf extract, T5: sausage with $0.2 \%$ chlorogenic acid standard. Different letters indicate significant difference at $p<0.05$. 
interactions. Presumably, the change in the chlorogenic acid content in ETS during in vitro human digestion may also have influenced various bioactive properties. However, the nature of the alterations in the chemical structures, polymer chain lengths, and molecular weight of phenolics during in vitro human digestion are hitherto unknown, which necessitates further detailed studies.

The antioxidant activity in ETS containing chlorogenic acid standard (T5) was higher than that in ETS containing BLE from the different cultivars (T1-T4) during in vitro human digestion (Fig. 3). The antioxidant activity differed among the ETS containing BLE from the different cultivars, with ETS containing Northland BLE displaying the highest activity and ETS containing Duke BLE showing the least activity. In general, the high antioxidant activity of blueberry extracts may be related to the high levels of polyphenolic compounds (Molan et al., 2008). In the present study, we also found that during in vitro human digestion, the antioxidant activity of ETS containing blueberry extract depended on the amount of phenolic compound (chlorogenic acid).

Previous work (Marques and Farah, 2009) has shown that chlorogenic acids are antioxidant components produced by plants in response to environmental stress conditions such as infections by microbial pathogens, mechanical wounding, and excessive levels/intensities of UV or visible light. The results from the present study also showed that the antioxidant activity increased with increasing chlorogenic acid content in ETS containing BLE. These findings suggest that the antioxidant activity of all ETS containing BLE may be less influenced by in vitro human digestion and that the antioxidant activity of ETS depended on the chlorogenic acid content.

According to an earlier study (Su and Chien, 2007), other factors such as oxygen, enzymes, and temperature also influence phenolic compositions and antioxidant activities of blueberry products. The bioavailability of polyphenols to peripheral tissues may be lowered by high intestinal and biliary secretion of their conjugates (Bermúdez-Soto et al., 2007; Silberberg et al., 2006). In the present study, the chlorogenic acid content decreased slightly when the ETS containing BLE moved from the simulated stomach to the small intestine, which may be due to variation in the enzymes, $\mathrm{pH}$, or oxygen levels, and this change in the chlorogenic acid content can influence the antioxidant activity in ETS containing BLE during in vitro human digestion. Zheng and Wang (2002) reported that chlorogenic acid was the major contributor to antioxidant activity owing to its high concentration in blueberry, and the antioxidant activity of chlorogenic acid is associated to some extent with the number of hydroxyl groups in their molecular structure (Zheng and Wang, 2002). Increased ability to donate a hydrogen atom from the hydroxyl group to a free radical is the factor responsible for the antioxidative activity of chlorogenic acid in the current investigation. Thus, compounds from blueberry leaves may have important applications in the future as natural antioxidants for meat products.

\section{Conclusions}

In the present study, simulated mouth, stomach, and small intestine digestion of ETS containing BLE was carried out to determine the stability of phytochemicals and antioxidant activities under in vitro human digestion conditions. A single phenolic compound (chlorogenic acid) was detected in the BLE. A change in the amount of chlorogenic acid occurred when the ETS containing BLE moved from the simulated stomach to the small intestine. Antioxidant activities were not influenced by in vitro human digestion in any of the tested ETS containing BLE, whereas the antioxidant activity of the chlorogenic acid standard increased in response to in vitro human digestion. Moreover, the results indicated that the antioxidant activity increased with increased chlorogenic acid content in the ETS containing BLE, suggesting that the antioxidant activities of all the BLE were not strongly influenced by in vitro human digestion and that the antioxidant activity depended on the chlorogenic acid content of ETS.

\section{Acknowledgements}

This paper was supported by the SMART Research Professor Program of Konkuk University.

\section{References}

1. Anonym. (2013). Blueberry variety review. Nate Nourse Nourse Farms. http://www.newenglandvfc.org/pdf_proceedings/Blueberry Variety.pdf Accessed Aug. 21, 2013

2. Bermúdez-Soto, M. J., Tomás-Barberán, F. A., and GarcíaConesa, M. T. (2007). Stability of polyphenols in chokeberry (Aronia melanocarpa) subjected to in vitro gastric and pancreatic digestion. Food Chem. 102, 865-874.

3. Ehlenfeldt, M. K., and Prior, R. L. (2001). Oxygen radical absorbance capacity (ORAC) and phenolic and anthocyanin concentrations in fruit and leaf tissues of highbush blueberry. J. Agr. Food Chem. 49, 2222-2227.

4. Hur, S. J., Decker, E. A., and McClements, D. J. (2009). Influence of initial emulsifier type on microstructural changes oc- 
curring in emulsified lipids during in vitro digestion. Food Chem. 114, 253-262.

5. Jeong, C. H., Choi, G. N., Kim, J. H., Kwak, J. H., Kim, D. O., Kim, Y. J., and Heo, H. J. (2010). Antioxidant activities from the aerial parts of Platycodon grandiflorum. Food Chem. 118, 278-282.

6. Kim, S. M., Shang, Y. F., Um, B. H. (2010). Preparative separation of chlorogenic acid by centrifugal partition chromagography from highbush blueberry leaves (Vaccinium corymbosum L.). Phytochem. Anal. 21, 457-462.

7. Marques, V., and Farah, A. (2009). Chlorogenic acids and related compounds in medicinal plants and infusions. Food Chem. 113, 1370-1376.

8. McDougall, G. J., Fyffe, S., Dobson, P., and Stewart, D. (2005). Anthocyanins from red wine - Their stability under simulated gastrointestinal digestion. Phytochem. 66, 2540-2548.

9. Molan, A. L., Lila, M. A., and Mawson, J. (2008). Satiety in rats following blueberry extract consumption induced by appetite-suppressing mechanisms unrelated to in vitro or in vivo antioxidant capacity. Food Chem. 107, 1039-1044.

10. Naczk, M., Grant, S., Zadernowski, R., and Barre, E. (2006). Protein precipitating capacity of phenolics of wild blueberry leaves and fruits. Food Chem. 96, 640-647.

11. Prior, R. L., Cao, G., Martin, A., Sofic, E., McEwen, J., O'Brien, C., Lischner, N., Ehlenfeldt, M., Kalt, W., Krewer, G., and Mainland, C. M. (1998). Antioxidant capacity as influenced by total phenolic and anthocyanin content, maturity, and variety of Vaccinium species. J. Agr. Food Chem. 46, 2686-2693.

12. Sellappan, S., Akoh, C. C., and Krewer, G. (2002). Phenolic compounds and antioxidant capacity of georgia-grown blueberries and blackberries. J. Agr. Food Chem. 50, 2432-2438.

13. Silberberg, M., Morand, C., Mathevon, T., Besson, C., Manach, C., Scalbert, A., and Remesy, C. (2006). The bioavailability of polyphenols is highly governed by the capacity of the intestine and of the liver to secrete conjugated metabolites. Eur J. Nutr. 45, 88-96.

14. Stevenson, D. E., Cooney, J. M., Jensen, D. J., Zhang, J., and Wibisono, R. (2007). Comparison of the relative recovery of polyphenolics in two fruit extracts from a model of degradation during digestion and metabolism. Mol. Nutr. Food Res. 51, 939-945.

15. Su, M. S. and Chien, P. J. (2007). Antioxidant activity, anthocyanins, and phenolics of rabbiteye blueberry (Vaccinium ashei) fluid products as affected by fermentation. Food Chem. 104, 182-187.

16. Versantvoort, C. H. M., Oomen, A. G., Van de Kamp, E., Rompelberg, C. J. M., and Sips, A. J. A. M. (2005). Applicability of an in vitro digestion model in assessing the bioaccessibility of mycotoxins from food. Food Chem. Toxicol. 43, 31-40.

17. Weber, C. (2012). Blueberry variety review. Cornell University Fruit Resources. www.fruit.cornell.edu/berry Accessed Aug. 21, 2013.

18. Zheng, W., and Wang, S. Y. (2002). Oxygen radical absorbing capacity of phenolics in blueberries, cranberries, chokeberries, and lingonberries. J. Agr. Food Chem. 51, 502-509.

$\overline{\text { (Received 2013.7.10/Revised 2013.8.22/Accepted 2013.9.11) }}$ 